\title{
SCIENTIFIC REPORTS

\section{OPEN Corrosion prevention of commercial alloys by air-water interface grown, edge on oriented, ultrathin squaraine film}

Received: 4 February 2019

Accepted: 20 August 2019

Published online: 17 September 2019

\author{
Rajiv Kumar Pandey, Richa Mishra, Gopal Ji (D) \& Rajiv Prakash
}

Copper is one of the most demanded commercial metal/alloys in world market. The demand for copper in industries such as electrical, electronics, automobile, telecommunications, defence, etc. as well as in daily life has escalated in the recent years due to its versatile physical and chemical properties. However destruction of copper surface by any means, preferably corrosion, can limit its vast application. For protection from corrosion, various techniques are used to coat metal substrates with passivating materials. These techniques are either complex as well as expensive, or provide incomplete protection in acid media. To address these issues, floating film transfer method (FFTM) is utilized in this work for obtaining ultrathin film of squaraine (passivating molecule) as well as their easy and fast transfer over copper substrate. The squaraine film is deposited on copper substrate in layers, viz., 1 to 4 layers. The corrosion behavior is examined in $0.1 \mathrm{M} \mathrm{HCl}$ using electrochemical techniques as well as surface characterization techniques, which portray that copper corrosion is hampered in harmony with the layers deposited. Nearly $40 \%$ corrosion protection is reached for copper coated with 1 layer of squaraine. However, the protection is amplified up to $98 \%$ with 4 layers of squaraine, which clearly substantiates the supremacy of this coating method over reported methods of protection. This technique and the material (squaraine) are both for the first time being used in the field of corrosion protection. The easy growth of ultrathin film at air-water interface as well as its rapid transfer over substrate promotes use of FFTM for efficient corrosion protection on industrial scale.

Copper is a vital metal that is broadly used as a raw material in electronic, automobile, marine and domestic applications, such as, house wiring, ship hulls, under sea telephone cable, hydraulic tubing and propellers, because of its great bio-fouling resistance, corrosion resistance, mechanical strength and great electrical property $^{1,2}$. However, the important functional properties of copper deteriorate faster in solutions having high amount of chloride ions ${ }^{3,4}$. Hence, it is necessary to increase the shielding strength of copper against the attack of chloride ions. There are several ways of protecting copper from its corrosion in aqueous solution; however, the use of organic coatings is most widely acceptable and efficient method for the job. The film of organic materials covers the surface of copper substrate and prevents it from being corroded by creating a physical barrier for aqueous solutions. However, the effectiveness of surface coating towards protection depends on the quality of film (i.e. degree of compactness) that in turn, is highly governed by the method adopted for film formation. Hence, it is necessary to select appropriate methods of coating for high quality corrosion prevention.

A large number of technologies have been used for film formation on the substrate such as, drop casting, spin casting, inkjet printing, etc. ${ }^{5}$. These techniques though easy to operate, but have major drawbacks of small area applicability and poor film quality. The reason of poor quality can be quoted to poor cohesive interactions among the molecules due to their random orientation during the film formation. Another issue with such film forming techniques is the non-uniform thickness of the film, which does not allow strong adherence of the film onto the substrate and causes disintegration of the film at several spots. Hence, it is necessary to produce thin and compact film over the substrate. There are technologies such as, Langmuir Blodgett (LB) and Langmuir Schaefer (LS) that employ air-water interface for large area, uniform thin film formation with controlled orientation of

School of Materials science and Technology, Indian Institute of Technology (BHU), Varanasi, Uttar Pradesh, 221005, India. Correspondence and requests for materials should be addressed to G.J. (email: gopalji.rs.mst11@itbhu.ac.in) or R.P. (email: rajivprakash12@yahoo.com) 


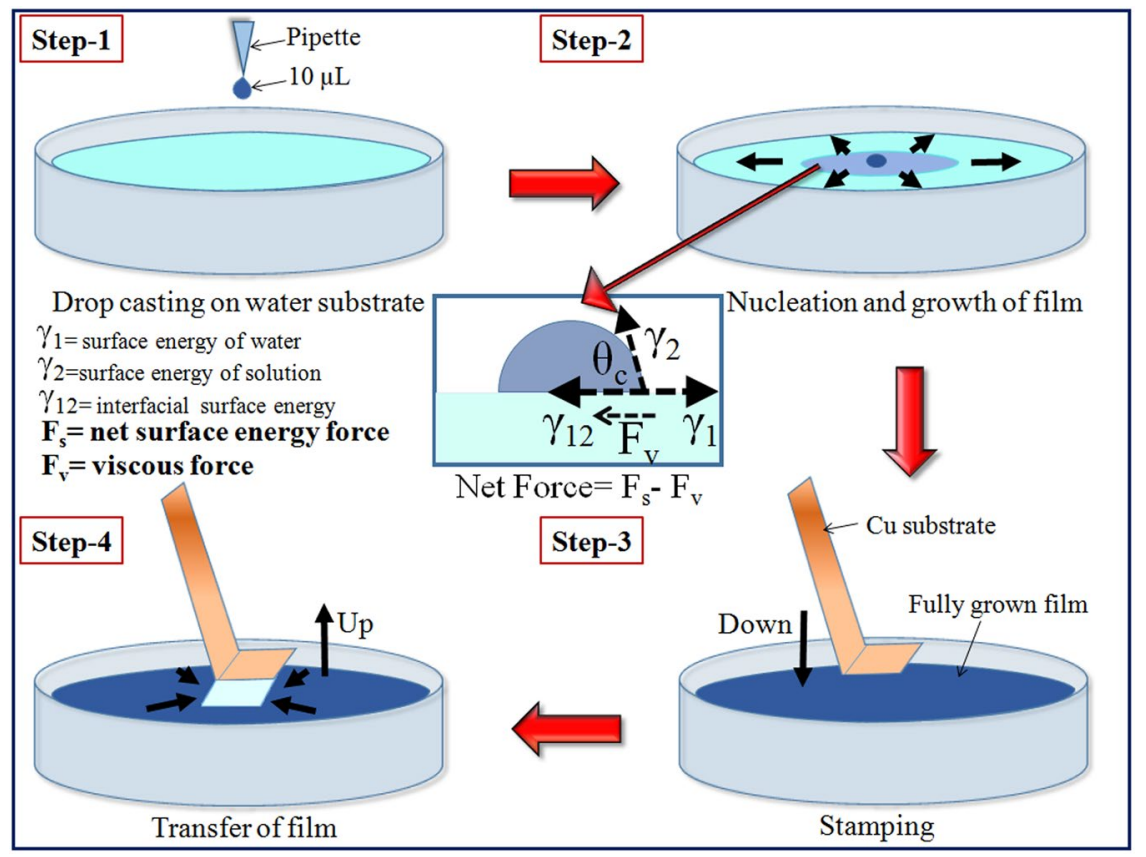

Figure 1. Schematic illustration of film formation by FFTM method and transfer of film over substrate.

the molecules ${ }^{6-9}$. However, LB and LS techniques involve complex instrumentation and hence lack behind for large scale commercial use. Chemical vapor deposition (CVD) is also a good technique for thin film deposition ${ }^{10}$. However, CVD film is associated with the problem of small pores that can act as active centers for corrosion reactions. This problem is smartly dealt by atomic layer deposition (ALD) technique that produces high quality compact film over the substrate ${ }^{10}$. However, both ALD and CVD require complex instrumentation and skilled person. Hence, large scale use of these techniques in corrosion area is not a cost effective solution of the problem.

To address above said issues, we are introducing Floating Film Transfer Method (FFTM) as a cost effective, high quality, large area and ultrathin film forming technique. This technique has close similarity with LS technique. The only technical difference is that LS technique requires application of pressure to the material's solution for the film formation, whereas FFTM utilize inherent surface energy of the solutions as a driving force for film formation. FFTM requires two solvents for formation of ultrathin film at air-liquid interface: first, volatile and low surface energy (hydrophobic) solvent and second, non-volatile and high surface energy (hydrophilic) solvent. Organic material, which has to be deposited, is soaked in volatile solvent in optimized amount and a small drop $(10-15 \mu \mathrm{L})$ of this solution is poured on hydrophilic surface. Due to surface energy difference, an ultrathin $(\sim 16 \mathrm{~nm})$ film is formed at air-liquid interface (Fig. 1). The floating film is then easily transferred to the substrate by simple stamping like LS technique. Thus, it can be said that FFTM can be considered as a combination of drop cast and LS technique ${ }^{11,12}$. Details of this technique can be accessed in these reports ${ }^{13-16}$ and results section of this manuscript. One of the reports claims that FFTM can be used in large area applications, which makes this technique a strong contender in the coating industry ${ }^{17}$.

The aim of current work is to investigate the prevention of copper corrosion in chloride rich environment through copper substrates coated with squaraine (SQR) thin films formed by FFTM technique. As explained in above paragraph, FFTM is a cost effective technique producing high quality ultrathin films with large surface coverage which is being explored for the first time in corrosion prevention applications. SQR dye has a quadrupolar cyclobutadione $\left(\mathrm{C}_{4} \mathrm{O}_{2}\right)$ central unit in its structure. The name 'squarine' to dye is given based on this square central unit. SQR belongs to the class of dyes that are widely known for their strong absorption and emission characteristics in longer wavelength region, wonderful stability under ambient conditions and very simple synthesis protocols ${ }^{18,19}$. Accordingly, it has been successfully implemented in gas sensors, bio-imaging probes, photodynamic therapy, nonlinear optics, organic solar cells and many other remarkable applications ${ }^{20,21}$. However, SQR has not been used for corrosion prevention of copper till date as per the best of our knowledge. SQR has very interesting chemical structure. It has hydrophobic functional group at one end and hydrophilic functional group at other end, which are connected to the square central unit in middle. This property renders its dissolution in both hydrophobic and hydrophilic solvent, which is good for producing films by FFTM. Metal surfaces are believed to be hydrophilic. This builds a possibility that hydrophilic portion of SQR can interact with surface, while other hydrophobic end will be in air. Thus, SQR modified metal surface will repel corrosive molecules and impart extra protection to metal. SQR contains nitrogen and oxygen lone pair of electrons that are shared with metal, resulting in strong bonding between SQR and metal. This is desirable for long term stability of films transferred onto metal surface. Further, these SQR coated metal surfaces have been checked for their corrosion prevention ability in $1 \mathrm{M} \mathrm{HCl}$ by single sine electrochemical impedance spectroscopy (SSEIS), Tafel polarization curves, differential pulse voltammetry (DPV), optical microscopy, HRSEM, EDAX, HRTEM, Uv-Vis 


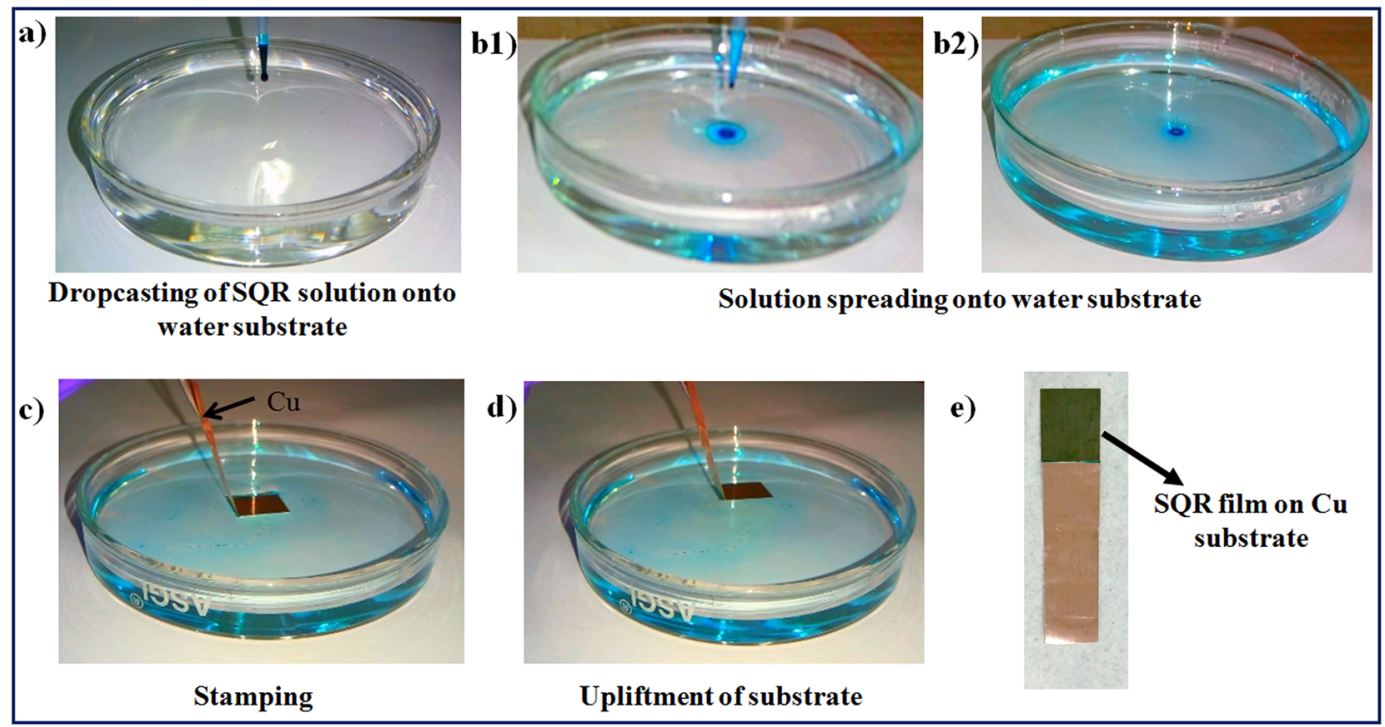

Figure 2. Real time images of film formation by FFTM method and transfer of film over Cu substrate.

spectroscopy, photo luminescence spectroscopy, FTIR spectroscopy, XRD and GIXRD techniques. The results show that few nanometers thick SQR film is highly efficient in prevention of copper loss in $\mathrm{HCl}$, which strongly encourages industrial use of FFTM in corrosion prevention.

\section{Results}

Growth of film at air-water interface. It is very important here to discuss the growth mechanism of the film formed at air-water interface that will help in understanding the importance of particular orientation of molecules required for proper adhesion to the substrate. There are two solvents involved in this FFTM i.e. low surface energy solvent (LSES) and high surface energy solvent (HSES). The movement of LSES over HSES can be explained with 'Marangonian flow' concept ${ }^{15}$. A schematic presentation to describe this phenomenon is already shown in Fig. 1. A drop of LSES over HSES generates surface tension gradient at the interface of two immiscible liquids. This gradient promotes the spreading of LSES along the surface towards the regions of higher strain surface in centrifugal manner. Another important parameter simultaneously operating during spreading process is the viscosity of HSES. The viscosity of HSES opposes spreading of LSES over it. Hence, spreading of LSES is regulated by both surface tension gradient and viscosity of HSES as per equation: $S S=F_{D}-F_{V}$. In this equation, $\mathrm{SS}$ is termed for spontaneous spreading of hydrophobic solvent, $\mathrm{F}_{\mathrm{D}}$ is driving force that depends on the surface tension gradient and $F_{V}$ is viscous force arising from viscosity of HSES. The driving force $F_{D}$ can be further explained with a term spreading coefficient (S). This coefficient determines the possibility of spreading of one solvent over the other for film formation. Spreading coefficient is defined as $S=\gamma_{1}-\gamma_{2}-\gamma_{12}$, where $\gamma_{1}$ represent the surface energy of hydrophilic solvent, $\gamma_{2}$ shows surface energy of the solution of material (to be deposited) in hydrophobic solvent and $\gamma_{12}$ express the surface energy of the interface ${ }^{15}$. For spreading of the film, $S$ must be greater than 0 . Hence, both the solvents should be selected accordingly. It is evident from above discussion that hydrophilic solvent acts as substrate for deposition of the material's film. In our case $\gamma_{1}$ (water) is $72 \mathrm{mN} \mathrm{m}^{-1}, \gamma_{2}$ (chloroform) is $27.5 \mathrm{~m} \mathrm{~m}^{-1}$ and $\gamma_{12}$ is $31.6 \mathrm{mN} \mathrm{m}^{-115}$. Then, $\mathrm{S}$ is calculated as $12.9 \mathrm{mN} \mathrm{m}^{-1}$ (spreading speed 3.4 $\sqrt{ } \mathrm{Kg} / \mathrm{s}^{2}$ ), which is greater than zero and shows validity of solvent selection for film formation. Real time images of film formation by FFTM method and transfer of film over $\mathrm{Cu}$ substrate are shown in Fig. 2.

Characterization of squaraine. The most reliable characterization of SQR is the identification of the central unit of $\mathrm{C}_{4} \mathrm{O}_{2}{ }^{18,19}$. The central ring is basically an electron deficient ring and behaves as a donor- $\pi$-acceptor- $\pi$-donor system. The delocalization of the charge occurs over the entire molecule, which can be presented in different forms (I, II and III) as shown in Fig. 3A.

For basic characterization of SQR, one layer of SQR film was transferred on quartz substrate by FFTM and studied by UV-vis and PL spectroscopy (Fig. 3B). In UV-vis spectrum, a sharp absorption band appeared at $686 \mathrm{~nm}\left(\lambda_{\max }\right)$ in the long wavelength region, which exhibited $\pi-\pi^{*}\left(\mathrm{~S}_{1}-\mathrm{S}_{0}\right)$ transitions corresponding to the central ring $\left(\mathrm{C}_{4} \mathrm{O}_{2}\right)$. A hypsochromic vibronic shoulder also appeared at $625 \mathrm{~nm}$, which could indicate dye aggregation. The emission spectra of SQR showed two peaks at 728 and $743 \mathrm{~nm}$, which projected that SQR was emitting in NIR frequency range ${ }^{18-23}$. Furthermore, functionality of SQR as well as its interaction with Cu substrate was validated by FTIR spectroscopy. Both SQR in powder form and as coated on $\mathrm{Cu}$ are examined and related FTIR spectra are presented in Fig. 3C. In the spectrum of SQR, the characteristic peak of saturated carboxylic acid $\left(\mathrm{C}=\mathrm{O}\right.$ stretching) appeared at $1728 \mathrm{~cm}^{-1}$. Whereas, $\mathrm{C}=\mathrm{O}$ stretching peak shifted towards lower wave number $\left(1695 \mathrm{~cm}^{-1}\right)$ for SQR FTM film (Fig. 3C). This shift in $\mathrm{C}=\mathrm{O}$ stretching peak clearly signified the interaction between $\mathrm{Cu}$ and $\mathrm{SQR}$ via hydrophilic carboxylic $(\mathrm{C}=\mathrm{O}) \mathrm{end}^{24}$. Furthermore, raman spectroscopy investigation of weak $\mathrm{C}=\mathrm{O}$ peak at $1710 \mathrm{~cm}^{-1}$ ascertained the interaction between $\mathrm{Cu}$ substrate and hydrophilic carboxylic end of SQR dye. Due to polarizability variation during the vibrational mode, a weak but clear $\mathrm{C}=\mathrm{O}$ band appeared in 

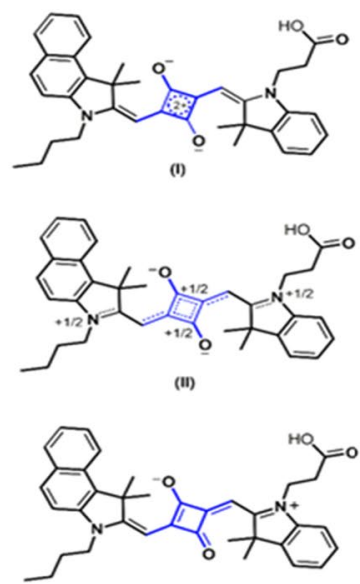

(iii)

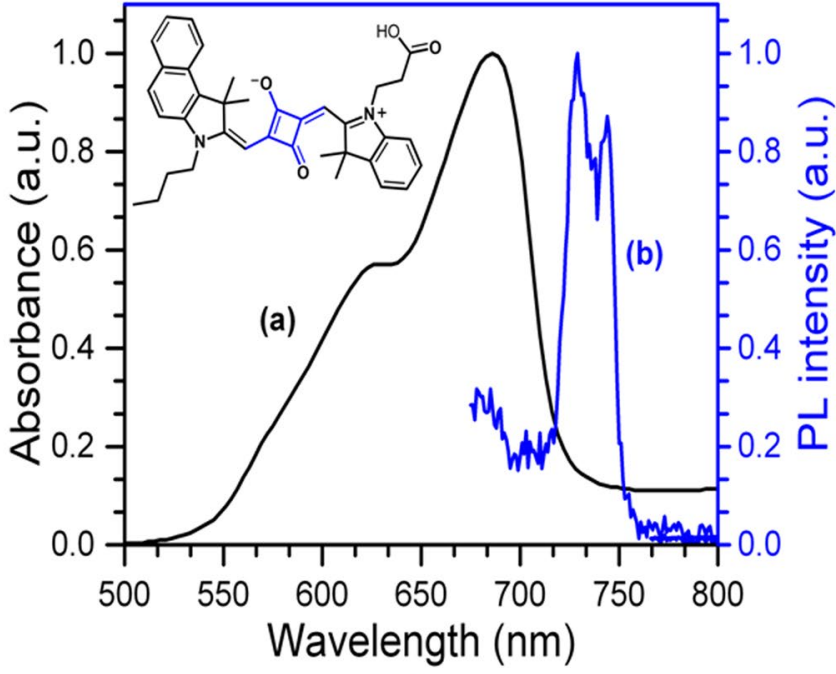

(B)

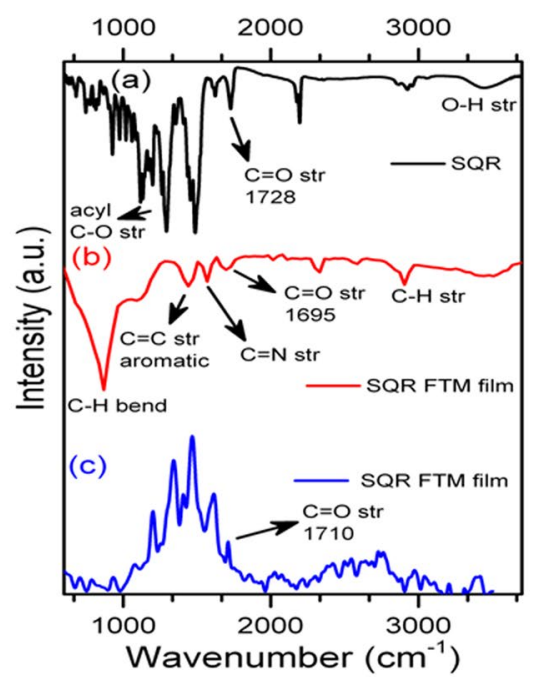

(C)

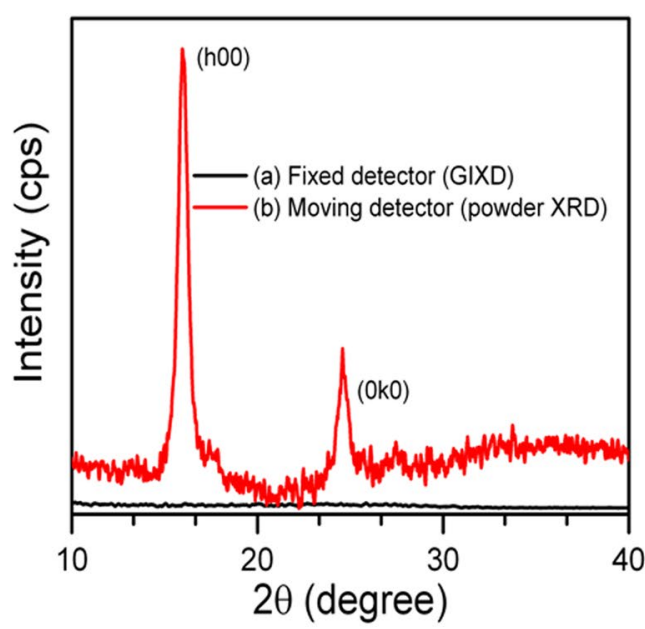

(D)

Figure 3. (A) Delocalization of the charge over entire SQR molecule and different forms (I, II and III). (B) UVvis and PL spectra of SQR. Inset- chemical structure of SQR, (C) FT-IR of (a) free SQR, (b) SQR FTM film and (c) Raman spectra of SQR FTM film and (D) GIXRD spectra of SQR coated substrate as well as XRD spectra of SQR.

the spectrum ${ }^{25}$. Thus, UV-vis and FTIR analysis together confirmed that SQR was successfully transferred over $\mathrm{Cu}$ substrate and its hydrophilic $\mathrm{C}=\mathrm{O}$ group was attached to the substrate.

To examine self-assembly and orientation in the SQR film, XRD spectrum was recorded in two modes as shown in Fig. 3D. First mode was powder XRD, where detector was fixed while source was moving with $2 \theta$ with respect to sample. The second mode was GIXD of pristine films with $0.2^{\circ}$ grazing angle (equipped with in plane diffractometer and out of plane moving detector). GIXD pattern of SQR film did not show any peak. However, powder XRD displayed two intense peaks at $15.96^{\circ}$ and $24.57^{\circ}$, which could be indexed as (h00) and (0k0) diffraction peak of SQR ${ }^{23,26}$. The interplanar spacing of $(010)$ planes of SQR film was found to be $0.36 \mathrm{~nm}$. Peak absence in GIXD of SQR film might be observed due to orientation (stacking) of molecules in a particular direction. Peak intensity investigation of pure SQR revealed well-grown and highly oriented domain rich films without thermal preparation as also complemented by HR-TEM and SAED images discussed below.

HRTEM images and SAED pattern were recorded to examine the morphology, crystallinity and most important the orientation of as deposited film. It is noteworthy here that SQR film thickness of $10-20 \mathrm{~nm}$ and sub $\mathrm{mm}$ size can form free standing film ${ }^{23}$. Low magnification HRTEM image of free standing film (Fig. 4A) revealed that well large crystallites of SQR were formed. SAED pattern of the same region also authenticated crystalline nature of SQR film. Further, investigation of the same region of free standing SQR film via high magnification HRTEM (Fig. 4B) demonstrated that SQR was aligned along (0k0) plane, which notified $\pi-\pi$ stacking of SQR. In order to show focus of the beam on sample area in HRTEM, Fast Fourier Transform (FFT) (Fig. 4B-inset) of same region 

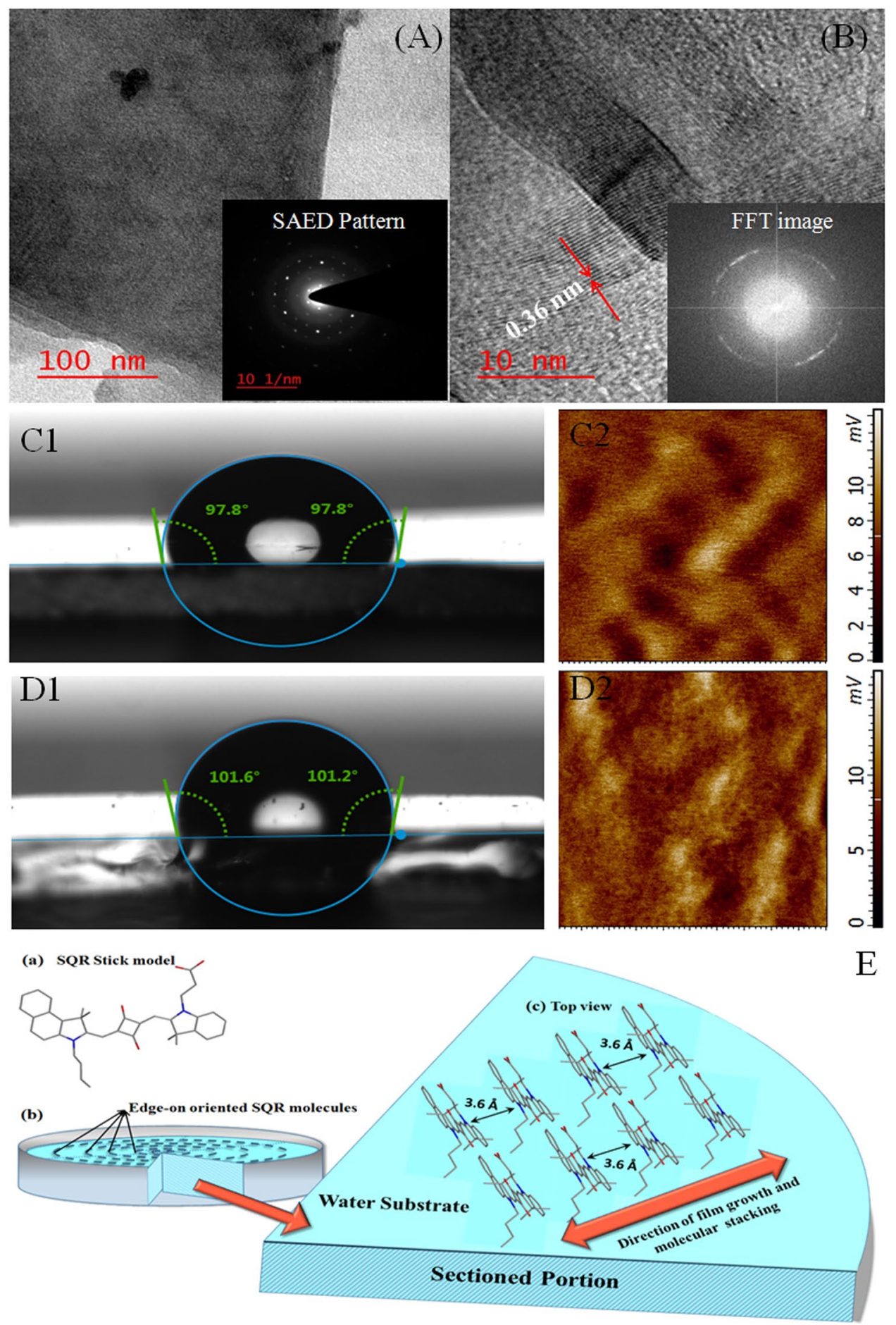

Figure 4. HRTEM images at (A) low magnification and (B) high magnification. Inset- (A) SAED pattern and (B) FFT of same region, surface energy/contact angle and KPFM measurements of SQR casted ITO substrate with $(\mathbf{C 1}, \mathbf{C} 2)$ hydrophilic end upside (D1,D2) hydrophobic end upside and (E) schematic illustration of film growth over water substrate and molecular stacking (a) SQR stick model, (b) edge on stacking and (c) growth of SQR molecules.

was recorded which validated the formation of $\pi-\pi$ stacked structure. Brinkmann et al. ${ }^{27}$ has already reported highly oriented crystalline films of other molecules with edge-on lamellar morphology, similar to as obtained in this case. The spacing between the lattice fringes was measured and found to be $0.36 \mathrm{~nm}$, which was equivalent to d-spacing of (010) plane or $\pi-\pi$ stacking distance of SQR backbones as discussed above in XRD results. This confirmed that $\pi-\pi$ stacked lamellar structure of polymer backbones with edge-on arrangement was present in film over the substrate, which was highly desirable for adherence and protection of surface. 

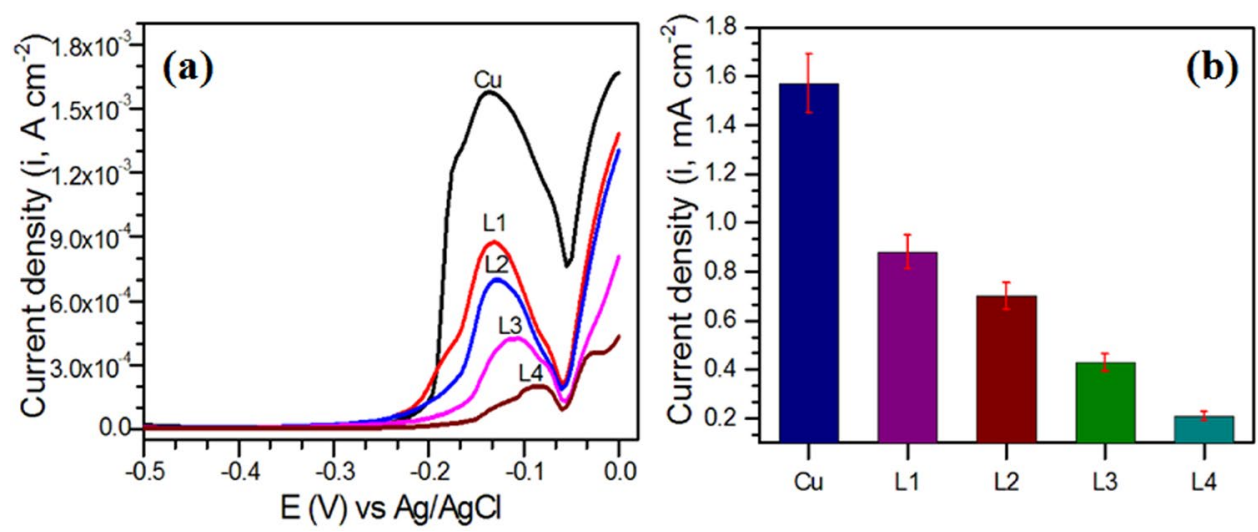

Figure 5. (a) DPV curves showing oxidation behavior of $\mathrm{Cu}$ substrates coated with different layers of SQR and (b) corresponding peak oxidation current.

It is important to note that HR-TEM exhibited $\pi-\pi$ stacking of the planes. However, powder XRD showed (h00) and (0k0) planes which highly confirms the edge-on orientation of SQR film. As per literature, organic molecules form a stable film with alkyl chain lying over high energy surface ${ }^{23}$. Therefore, SQR film will be energetically stable only with alkyl side chain lying over the water substrate. In this scenario $\mathrm{COOH}, \mathrm{O}$ and $\mathrm{N}$ present in plane of molecule will interact with high energy surface (water substrate) during deposition via horizontal stamping and alkyl group will be exposed to the external ambient. Thus, alkyl group will minimize the energy imbalance. The edge-on orientation is highly desirable for planar surface protection due to the presence of $\mathrm{COOH}, \mathrm{O}$ and $\mathrm{N}$ in plane of molecule.

Figure 4C,D present the surface contact angles and corresponding KPFM images of the SQR film lifted in two ways. Figure 4C1,C2 is for SQR film (type I) lifted by dipping the substrate first into the water subphase, then slowly lifting the floating SQR film from below the water subphase. Whereas Fig. 4D1,D2 show images for SQR film (type II) lifted via tapping of the substrate from upside over the water subphase. We are assuming that type ISQR film is hydrophilic (that adheres to the Cu substrate coated for all investigations) and type II film is comparatively hydrophobic in nature (also acts as surface of modified $\mathrm{Cu}$ substrate). Surface contact angle measurements clearly justified our assumption that type I film is hydrophilic and type II film is hydrophobic ${ }^{23,28}$. Although surface contact angle is greater than $90^{\circ}$ for both kind of films, yet we can say that more hydrophilic part of the film adheres to the hydrophilic $\mathrm{Cu}$ substrate. This fact was also confirmed by KPFM images of SQR film. The scale of voltage is slightly higher for type II SQR film, which revealed that acid exposed surface of SQR modified Cu is hydrophobic again strengthening our assumption. Based on the above results, a schematic has been designed about SQR structure, film growth and its orientation \& stacking in the film, and presented in Fig. 4E(a-c).

Characterization of SQR coated copper substrates. SQR film was formed at air-water interface by FFTM and four layers (1, 2, 3 and 4) of SQR were transferred over Cu substrate. HRSEM images, EDAX mappings and differential pulse voltammetry (DPV) measurements were recorded to ensure the transfer of the film over $\mathrm{Cu}$ substrates. Figure S1 (Supporting Information) shows HRSEM images and corresponding EDAX mappings of polished $\mathrm{Cu}$ as well as SQR coated $\mathrm{Cu}$ substrates. HRSEM images did not find any remarkable difference in surface morphology between $\mathrm{Cu}$ and SQR coated $\mathrm{Cu}$. However, EDAX mappings revealed that concentration of $\mathrm{C}$ and $\mathrm{N}$ increased with the number of layers transferred. This fact was also confirmed by EDAX spectra of the same regions (Table S1, Supporting Information). Thus, it was evident that the layers were successfully transferred over Cu substrates.

To have preliminary idea about prevention ability of SQR, DPV analysis of the coated substrates were performed. The DPV curves for Cu and SQR coated Cu are presented in Fig. 5a,b. The oxidation current was lowered for SQR coated copper substrates. Also, the peak was shifted towards positive values with the number of layers. Both the facts indicated that SQR was successfully transferred over copper and prevented its dissolution in $0.1 \mathrm{M}$ $\mathrm{HCl}^{29}$. The maximum reduction in current values ( 8 times) and shifting of oxidation peaks was achieved with 4 layers of SQR over copper. Besides, analysis of corroded copper and SQR coated copper were performed by HRSEM and EDAX techniques and shown in Fig. S3 (Supporting Information). The images portrayed that $\mathrm{HCl}$ attacked at several places on copper surface, which caused severe corrosion of copper and appeared as if it was broken at several places. In contrast, the surface morphology of the SQR coated copper substrates projected that corrosion of copper was seriously stopped; however, the prevention ability of 1 layer SQR coated Cu was the least and increased significantly with increase in the number of layers. EDAX mappings of copper substrates projected that corroded surfaces were covered with $\mathrm{C}, \mathrm{N}$ and chloride. The maximum chloride concentration was found on corroded copper, while it was severely decreased for SQR coated $\mathrm{Cu}$. Also, concentration of $\mathrm{C}$ and $\mathrm{N}$ was the highest for 4 layers SQR coated $\mathrm{Cu}$ and decreased with number of layers. These facts suggested that prevention of $\mathrm{Cu}$ loss (dissolution) in $\mathrm{HCl}$ was achieved in accordance with the layers transferred over $\mathrm{Cu}$ substrates. 

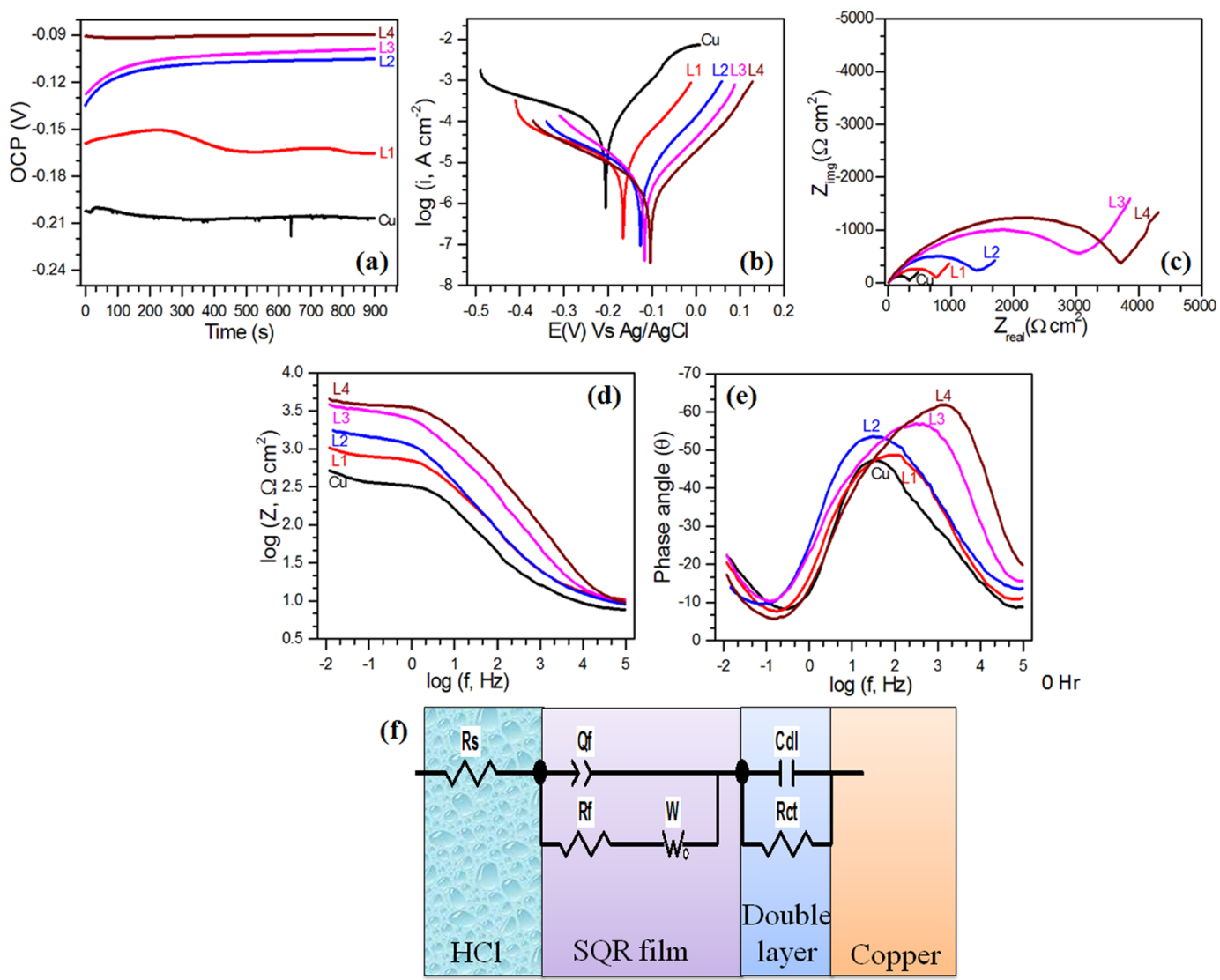

Figure 6. (a) OCP curves. (b) Tafel polarization curves of $\mathrm{Cu}$ and $\mathrm{SQR}$ coated $\mathrm{Cu}$ substrates after $15 \mathrm{~min}$ immersion in $0.1 \mathrm{M} \mathrm{HCl}$ at $299 \pm 2 \mathrm{~K}$. (c) Nyquist plot. (d) Bode modulus plots and (e) Bode phase plots of Cu and SQR coated $\mathrm{Cu}$ substrates after $15 \mathrm{~min}$ immersion in $0.1 \mathrm{M} \mathrm{HCl}$ at $299 \pm 2 \mathrm{~K}$. (f) Circuit model used for fitting the response curves.

\section{Discussion}

Figure 6a,b presents open circuit potential (OCP) curves and Tafel curves for $\mathrm{Cu}$ as well as SQR coated copper substrates obtained in $0.1 \mathrm{M} \mathrm{HCl}$. For $\mathrm{Cu}$, OCP was slightly positive at $0 \mathrm{~min}$ in comparison to OCP at $15 \mathrm{~min}$. This could predict that pristine $\mathrm{Cu}$ was having a layer of copper oxide on the surface, which was obviously expected. This layer could not withstand acidic environment $(0.1 \mathrm{M} \mathrm{HCl})$ after some time, as it got disrupted and thus could not protect $\mathrm{Cu}$. OCP curve of $1 \mathrm{~L}-\mathrm{SQR}$ coated $\mathrm{Cu}$ suggested that SQR was preventing corrosion as the potential of $\mathrm{Cu}$ substrate shifted towards positive values vs. pristine $\mathrm{Cu}^{30}$. However, the shape of OCP curve further indicated that $1 \mathrm{~L}-\mathrm{SQR}$ could not cover the whole surface of $\mathrm{Cu}$. OCP curves of $2 \mathrm{~L}-\mathrm{SQR}$ and $3 \mathrm{~L}-\mathrm{SQR}$ coated $\mathrm{Cu}$ substrates were found more positive than pristine $\mathrm{Cu}$ and $1 \mathrm{~L}-\mathrm{SQR}$ coated $\mathrm{Cu}$, which suggested that surface coverage increased with the subsequent layering of SQR. Further, OCP curve for $4 \mathrm{~L}-\mathrm{SQR}$ coated Cu was almost constant for $15 \mathrm{~min}$, with the highest positive value among all. This indicated that fourth layering of SQR over Cu covered its area to maximum thus preventing its corrosion with the best capacity. This explanation of prevention was done based on following equation ${ }^{31}$ :

$$
T=1-\delta^{N}
$$

where $T$ indicates density of uncovered points on the surface, $\delta$ relates with defects density and $N$ is numbers of coated layers. This equation suggests that coverage of surface will subsequently increase with the number of layers transferred on the substrates, which supports our explanation. In any case, the potentials were showing more stability after $15 \mathrm{~min}$ in comparison to the beginning potential. Hence, Tafel and impedance experiments were performed only after $15 \mathrm{~min}$ of immersion of the substrates in $0.1 \mathrm{M} \mathrm{HCl}$.

Figure $6 \mathrm{~b}$ exhibits Tafel curves of pristine $\mathrm{Cu}$ and SQR coated $\mathrm{Cu}$ substrates, showing their polarization behavior. The curves exhibited shifting of potential (corresponding to the lowest current) towards more positive values for $\mathrm{SQR}$ coated $\mathrm{Cu}$ with reference to pristine $\mathrm{Cu}$. Also, the lowest point of current density (log i) curve shows a decreasing trend with subsequent layers indicating decreasing value of current. Both these observations validated the prevention of $\mathrm{Cu}$ corrosion by SQR coating in $0.1 \mathrm{M} \mathrm{HCl}^{29,30}$. For better insight, Tafel curves were fitted by $\mathrm{CHI}-7041 \mathrm{C}$ software (CH instruments, USA) and the exact parameters obtained are reflecting quantified changes in corrosion behavior of $\mathrm{Cu}$. The parameters were: equilibrium corrosion potential, $\mathrm{E}_{\text {corr }}$; corrosion 


\begin{tabular}{|l|l|l|l|l|l|l|l|}
\hline Substrate & $\begin{array}{l}-\mathbf{E}_{\text {corr }} \\
(\mathbf{m V})\end{array}$ & $\begin{array}{l}\mathbf{I}_{\text {corr }} \\
\left(\boldsymbol{\mu A} \mathbf{c m}^{-2}\right)\end{array}$ & $\begin{array}{l}\mathbf{b}_{\mathbf{a}} \\
\left(\mathbf{m v} \mathbf{d e c}^{-1}\right)\end{array}$ & $\begin{array}{l}-\mathbf{b}_{\mathbf{c}} \\
\left(\mathbf{m v} \mathbf{d e c}^{-1}\right)\end{array}$ & $\begin{array}{l}\boldsymbol{\mu}_{\mathrm{p}} \\
(\%)\end{array}$ & $\begin{array}{l}\mathbf{R}_{p} \\
\left(\boldsymbol{\Omega} \mathbf{c m}^{2}\right)\end{array}$ & $\begin{array}{l}\boldsymbol{\mu}_{\mathrm{Rp}} \\
(\%)\end{array}$ \\
\hline Cu_Blank & 190 & 86 & 90 & 234 & - & 331 & - \\
\hline Cu_1L SQR & 161 & 12 & 85 & 233 & 86 & 2247 & 85 \\
\hline Cu_2L SQR & 119 & 5 & 89 & 183 & 94 & 5221 & 94 \\
\hline Cu_3L SQR & 105 & 3 & 94 & 125 & 97 & 7184 & 95 \\
\hline Cu_4L SQR & 091 & 2 & 93 & 166 & 98 & 11093 & 97 \\
\hline
\end{tabular}

Table 1. Corrosion parameters obtained from Tafel polarization curves of $\mathrm{Cu}$ and SQR coated $\mathrm{Cu}$ substrates after $15 \mathrm{~min}$ immersion in $0.1 \mathrm{M} \mathrm{HCl}$ at $299 \pm 2 \mathrm{~K}$.

current density, $\mathrm{I}_{\text {corr }}$; anodic and cathodic curves slopes, $\mathrm{b}_{\mathrm{a}}$ and $\mathrm{b}_{\mathrm{c}}$; and polarization resistance, $\mathrm{R}_{\mathrm{p}}$. The prevention efficiencies based on $I_{\text {corr }}\left(\mu_{p}\right)$ and $R_{p}\left(\mu_{R p}\right)$ were determined according the following equations ${ }^{32}$ :

$$
\begin{aligned}
& \mu_{p}(\%)=\frac{I_{\text {corr }}^{0}-I_{\text {corr }}^{i}}{I_{\text {corr }}^{0}} \times 100 \\
& \mu_{R p}(\%)=\frac{R_{\mathrm{P}}^{\mathrm{i}}-R_{P}^{0}}{R_{\mathrm{P}}^{\mathrm{i}}} \times 100
\end{aligned}
$$

where superscripts ' $i$ ' and ' 0 'are used for SQR coated $\mathrm{Cu}$ and pristine $\mathrm{Cu}$ in $0.1 \mathrm{M} \mathrm{HCl}$, respectively.

Table 1 exhibits the changes in different parameters with the number of SQR layers transferred on $\mathrm{Cu}$ substrate. The $\mathrm{E}_{\text {corr }}$ of pristine $\mathrm{Cu}$ and $1 \mathrm{~L}-\mathrm{SQR}$ coated $\mathrm{Cu}$ were $-190 \mathrm{mV}$ and $-161 \mathrm{mV}$ respectively, which indicated that $\mathrm{SQR}$ was protecting $\mathrm{Cu}$ in $\mathrm{HCl}$ since $\mathrm{E}_{\text {corr }}$ was more positive ${ }^{33}$. With increase in the number of layers, $\mathrm{E}_{\text {corr }}$ started to move towards more positive potentials, which portrayed that thermodynamic stability of the system increased. The similar trend of shifts in potentials was also observed in OCP curves. The coating served as a physical barrier to $\mathrm{H}^{+}$and $\mathrm{Cl}^{-}$ions, that means reduction of $\mathrm{H}^{+}$to $\mathrm{H}_{2}$ and oxidation of $\mathrm{Cu}$ to $\mathrm{Cu}^{2+}$ was prevented by SQR film. It was noticed that $b_{c}$ was greater than $b_{a}$; and $b_{c}$ changed more than $b_{a}$ with increase in the numbers of layers, which documented that conversion of $\mathrm{H}^{+}$to $\mathrm{H}_{2}$ was more strongly prevented than oxidation of $\mathrm{Cu}$ to $\mathrm{Cu}^{2+34,35}$. Furthermore, prevention of corrosion reactions was directly significant from the $\mathrm{I}_{\text {corr }}$ values. $\mathrm{I}_{\text {corr }}$ value for pristine $\mathrm{Cu}$ was $86 \mu \mathrm{A} \mathrm{cm}^{-2}$, while it was $12 \mu \mathrm{Acm}^{-2}$ for $1 \mathrm{~L}-\mathrm{SQR}$ coated $\mathrm{Cu}$. Based on $\mathrm{I}_{\text {corr }}$ values, it was observed that efficiency of prevention was magnified with the number of layers as the openings on the $\mathrm{Cu}$ surface were reduced with multiple coatings (layers of the film). For $4 \mathrm{~L}-\mathrm{SQR}$ coated $\mathrm{Cu}, \mathrm{I}_{\text {corr }}$ was just $2 \mu \mathrm{A} \mathrm{cm}{ }^{-2}$ revealing only $2 \%$ corrosion of $\mathrm{Cu}$ in $0.1 \mathrm{M} \mathrm{HCl}$. The prevention efficiency of SQR could also be checked by comparing $\mathrm{R}_{\mathrm{p}}$ values. The polarization resistances of $\mathrm{SQR}$ coated $\mathrm{Cu}$ substrates were higher than pristine $\mathrm{Cu}$, which suggested that equilibrium of the substrates could not be disturbed easily. This intended that SQR coated Cu system was more stable towards corrosion reactions (either cathodic or anodic) and these reactions could not be accelerated straightforwardly as it could be done in case of pristine $\mathrm{Cu}$ in $\mathrm{HCl}^{36,37}$.

Figure 6c-e presents Nyquist, Bode modulus and Bode phase plots for pristine $\mathrm{Cu}$ as well as SQR coated $\mathrm{Cu}$ in $0.1 \mathrm{M} \mathrm{HCl}$. Bode modulus plots reveals that impedance of SQR coated Cu substrates was higher than pristine $\mathrm{Cu}$. The increase in quantity of impedance followed the number of layers and indicated that $4 \mathrm{~L}-\mathrm{SQR}$ coated $\mathrm{Cu}$ was giving the highest impedance. Bode phase plots showed that phase angle difference between applied voltage and current response was enhanced with the number of layers, which suggested that charge distribution on the surface was becoming more uniform. Both these observations advocated that corrosion of Cu was effectively prevented $^{38,39}$. Furthermore, Nyquist plots of pristine $\mathrm{Cu}$ and SQR coated $\mathrm{Cu}$ could be divided in two segments: first, big semi-circular loop; and second, line/incomplete loop in low frequency zone. These observations suggested that corrosion of either pure $\mathrm{Cu}$ or SQR coated $\mathrm{Cu}$ was two time constant process, revealing that two interfaces were formed between electrolyte and $\mathrm{Cu}$. This was also supported by bode phase angle plots. The size of response curves for $\mathrm{SQR}$ coated $\mathrm{Cu}$ was greater than for pure $\mathrm{Cu}$, which specified that $\mathrm{Cu}$ corrosion in hydrochloric acid was prevented by SQR film ${ }^{40,41}$. Also, the increase in size followed the number of layers on Cu substrate, which clearly signified that corrosion was prevented in a better way with three or four layers of SQR over Cu.

To quantify the effects of SQR layers on Cu corrosion, impedance curves were fitted with a circuit model shown in Fig. $6 \mathrm{f}$. As per the model, the corrosion behavior could be defined with following parameters: solution resistance, $R_{s}$; constant phase capacitance of SQR film, $Q_{f}$; resistance of SQR film/oxide film (in case of pristine $\mathrm{Cu}), \mathrm{R}_{\mathrm{f}}$; double layer capacitance of acid-cu interface, $\mathrm{C}_{\mathrm{d}}$; and charge transfer resistance of acid-Cu interface, $\mathrm{R}_{\mathrm{ct}}$. The total resistance (impedance, $\mathrm{Z}$ ) of the circuit can be described by the equation:

$$
Z=R_{s}+\frac{1}{(j w)^{\alpha} Q_{f}+\frac{1}{R_{f}+\frac{(1-j) W}{\sqrt{ } \omega}}}+\frac{1}{j \omega C_{d l}+\frac{1}{R_{c t}}}
$$

where $\mathrm{j}$ is $\sqrt{ }-1$ and $\alpha$ denotes quality of charge distribution on the surface. In the equation, first term is for solution, second term is for SQR film and third term is for corrosion reactions at acid-Cu interface. All the experiments were performed in $0.1 \mathrm{M} \mathrm{HCl}$; hence, $\mathrm{HCl}$ was test solution and corresponded to $\mathrm{R}_{\mathrm{s}}$ in the circuit, as per conventional circuit fitting procedures. Second term was assigned to SQR film because it was the first interface formed between solution and $\mathrm{Cu}$ surface. Third term is assigned to acid-Cu interface because it was the second 


\begin{tabular}{|l|l|l|l|l|l|l|l|l|l|l|}
\hline Substrate & $\begin{array}{l}\mathbf{R}_{\mathbf{s}} \\
\left(\boldsymbol{\Omega} \mathbf{c m}^{2}\right)\end{array}$ & $\begin{array}{l}\mathbf{Q}_{\mathrm{f}} \\
\left(\boldsymbol{\mu S . s ^ { \boldsymbol { \alpha } } )}\right.\end{array}$ & $\boldsymbol{\alpha}$ & $\begin{array}{l}\mathbf{R}_{\mathbf{f}} \\
\left(\boldsymbol{\Omega} \mathbf{c m}^{2}\right)\end{array}$ & $\begin{array}{l}\mathbf{W} \\
\left(\mathbf{S} . \mathbf{s}^{\mathbf{0 . 5}}\right)\end{array}$ & $\begin{array}{l}\mathbf{C}_{\mathrm{dl}} \\
\left(\boldsymbol{\mu F} \mathbf{c m}^{-2}\right)\end{array}$ & $\begin{array}{l}\mathbf{R c t} \\
\left(\boldsymbol{\Omega} \mathbf{~ c m}^{2}\right)\end{array}$ & $\begin{array}{l}\boldsymbol{\mu}_{\mathrm{r}} \\
(\%)\end{array}$ & $\chi^{\mathbf{2}}$ & $\begin{array}{l}\mathbf{Z}_{\text {error }} \\
(\%)\end{array}$ \\
\hline Cu_Blank & 7 & 900 & 0.529 & 136 & 0.0142 & 142 & 189 & - & $1.51 \times 10^{-3}$ & 3.88 \\
\hline Cu_1L SQR & 12 & 191 & 0.624 & 308 & 0.00862 & 170 & 198 & 36 & $2.31 \times 10^{-3}$ & 4.80 \\
\hline Cu_2L SQR & 8 & 316 & 0.582 & 959 & 0.00738 & 113 & 548 & 78 & $1.94 \times 10^{-3}$ & 4.40 \\
\hline Cu_3L SQR & 9 & 41 & 0.718 & 1353 & 0.00185 & 75 & 1319 & 88 & $1.27 \times 10^{-3}$ & 3.56 \\
\hline Cu_4L SQR & 8 & 16 & 0.753 & 1481 & 0.0024 & 23 & 1927 & 90 & $1.33 \times 10^{-3}$ & 3.64 \\
\hline
\end{tabular}

Table 2. Corrosion parameters obtained after fitting of the response curves of $\mathrm{Cu}$ and SQR coated $\mathrm{Cu}$ substrates after $15 \mathrm{~min}$ immersion in $0.1 \mathrm{M} \mathrm{HCl}$ at $299 \pm 2 \mathrm{~K}$ with circuit model.

interface formed between solution and $\mathrm{Cu}$ surface. This interface could form due to insufficient coverage of $\mathrm{Cu}$ substrate by SQR film. So, solution could reach to base substrate through openings in the film. The $\chi^{2}$ values for the fitting were sufficiently low $\left(10^{-3}\right.$ order) and fitting errors in $\mathrm{Z}$ measurements were less than $5 \%$, which indicated that corrosion of both pristine $\mathrm{Cu}$ and $\mathrm{SQR}$ coated $\mathrm{Cu}$ in $0.1 \mathrm{M} \mathrm{HCl}$ could be confidently explained with the proposed model. The prevention efficiency of $S Q R$ was determined based on $R_{c t}$ values using the equation described below ${ }^{42}$.

$$
\mu_{R_{c t}}(\%)=\frac{R_{c t}^{i}-R_{c t}^{0}}{R_{c t}^{i}} \times 100
$$

where superscript 'i' and ' 0 ' are used to denote presence and absence of SQR film on Cu.

There were two zones on the Cu surface: first, covered with SQR; and second, openly accessible. Accordingly, electrolyte could reach to $\mathrm{Cu}$ substrate via micro pores of SQR film and openings of the surface. Data analysis of Table 2 disclosed that $\mathrm{Q}_{\mathrm{f}}$ values decreased while $\mathrm{R}_{\mathrm{f}}$ values raised with the number of $\mathrm{SQR}$ layers on $\mathrm{Cu}$, which indicated that prevention ability of SQR increased with increase in number of layers ${ }^{43,44}$. The reason could be quoted as decrease in the porosity of SQR film with the number of layers, which was responsible for reduced acidic exposure of $\mathrm{Cu}$ beneath the layers. Due to increase in local density, the resistance of film subsequently increased with the number of layers. In the circuit model, W (modulus of Warburg impedance) is also used in series with $\mathrm{R}_{\mathrm{f}}$. W is used to explain diffusion of electrolyte or diffusion of chloro-copper species through SQR/Cu corrosion products layering. The $\mathrm{W}$ values suggested that this reaction slowed down with the increase in number of layers. On the other side, corrosion reactions occurring at exposed surface could be analyzed through $\mathrm{C}_{\mathrm{dl}}$ and $R_{c t}$ values. The charge storage capacity of the acid-Cu interface $\left(C_{d l}\right)$ was significantly lowered with the number of layers on $\mathrm{Cu}$ substrate. This occurred as a result of decrease in number of surface openings, which actually indicated the higher surface coverage of $\mathrm{Cu}$ surface by SQR film. Accordingly, the charge transfer resistance also increased as the transport of charge across the acid-Cu interface was impeded by SQR film (barrier effect). Thus, it was observed that both $\mathrm{R}_{\mathrm{f}}$ and $\mathrm{R}_{\mathrm{ct}}$ participated to slow down the Cu corrosion in $0.1 \mathrm{M} \mathrm{HCl}$. Hence, prevention efficiencies based on impedance analysis were calculated from total resistance against corrosion $\left(\mathrm{R}_{\mathrm{f}}+\mathrm{R}_{\mathrm{ct}}\right)$. The enhancement in prevention efficiency showed combined effect of decrease in porosity of SQR film and reduction in number of surface openings with the increase in number of layers. Based on all above results and discussion, a schematic is illustrated in Fig. S4 (Supporting Information) to show the corrosion inhibition activity of SQR.

As a conclusion of the work, it can be said that this work focuses on the issues of thin and compact coating application for corrosion inhibition. A very new technique, never used before for corrosion prevention, FFTM is used to produce ultra-thin SQR film formed at air-water interface and transferred smoothly on Cu substrates. Thus coated $\mathrm{Cu}$ substrates were characterized with various techniques, and tested for prevention of corrosion by electrochemical and surface analysis techniques. UV-vis spectroscopy, PL spectroscopy and FT-IR spectroscopy confirmed that SQR used for the film formation was good in characteristics. Raman spectroscopy, HRTEM images, SAED pattern, live FFT image and XRD patterns revealed that SQR film formed at air-water interface was crystalline and highly ordered with long range $\pi-\pi$ stacking. Coated $\mathrm{Cu}$ substrates were preliminary examined by optical microscopy, HRSEM, EDAX and DPV techniques, which clearly showed that SQR layers were successfully transferred over $\mathrm{Cu}$ substrates and having a great influence on corrosion prevention efficiency of $\mathrm{Cu}$. Corrosion analysis was performed in detail by EIS and Tafel polarization techniques, which portrayed that corrosion of $\mathrm{Cu}$ in $0.1 \mathrm{M} \mathrm{HCl}$ was impeded in accordance with the layers transferred. The maximum corrosion prevention $(90 \%$, EIS and 98\%, Tafel curves) was acknowledged for Cu coated with 4 layers of SQR. The reason was very clear, i.e., the porosity of film decreased with increase in number of layers. Thus, the analysis strongly recommends FFTM as a new method of coating the base (metal) substrates for prevention towards corrosion. Although we have used $\mathrm{SQR}$ in this work, we can use many other cheap materials coated via FFTM for corrosion prevention.

\section{Methods and Materials}

Materials and preparation of the copper substrate. Thin $\mathrm{Cu}$ sheet of $99.9 \%$ purity was purchased from the metal market in Varanasi (India) and used as substrate material for this work. SQR Dye, chloroform, double distilled water (resistivity $=18.0 \mathrm{M} \Omega$ ) and $\mathrm{HCl}$ were purchased from Merck, India.

Preliminary preparation of $\mathrm{Cu}$ sheet was done by rubbing it with emery paper. This was performed in a sequence from low grade number to high grade number (1 to 5) emery paper of Sianor B, Switzerland. The sheet was rubbed in both parallel and perpendicular directions for 5 minutes with each number of emery papers. Then, the sheet was dip cleaned in $0.05 \mathrm{M} \mathrm{HCl}$ and immediately wiped with lint free tissue. As a final step, the sheet 
was abraded with emery paper of grade 6 . Thus prepared sheet was cut into specimens of $6 \times 1 \mathrm{~cm}^{2}$ and used as substrate for the study. For electrochemical investigation, only $1 \times 1 \mathrm{~cm}^{2}$ area of prepared specimens were exposed in acid and rest area was masked with $3 \mathrm{M}$ polyester tape, while $1 \times 1 \mathrm{~cm}^{2} \mathrm{Cu}$ substrates were used for surface morphology analysis.

Film formation and transfer over copper substrate. A glass petri dish $(\phi=8 \mathrm{~cm})$ was filled with distilled water up to $3 / 4$ of its height and upper water surface was cleaned multiple times with small strips of lint free tissue, to avoid any possible contaminations. One drop $(10 \mu \mathrm{L})$ of SQR solution in chloroform $\left(10 \mathrm{mg} \mathrm{mL}^{-1}\right)$ was released over water surface in the center and a circular floating film of blue color was formed at air-water interface within seconds. Then the floating film was carefully lifted on $\mathrm{Cu}$ strip $\left(6 \times 1 \mathrm{~cm}^{2}\right)$ and washed gently with a stream of distilled water followed by vacuum drying at $50{ }^{\circ} \mathrm{C}$ for $1 \mathrm{~h}$. Similarly, multiple layers (up to 4 layers) of SQR film were transferred over $\mathrm{Cu}$ substrate and investigated to collect details about layer dependent behavior of $\mathrm{Cu}$ corrosion prevention. A schematic presentation showing the real time images during the film formation is given in Fig. 2.

Preparation of the specimen for spectroscopic, XRD and surface analysis. Surface morphology of SQR deposited $\mathrm{Cu}$ substrates $\left(1 \times 1 \mathrm{~cm}^{2}\right)$ were investigated on HRSEM. Along with the fresh film samples, acid treated samples $(0.1 \mathrm{M} \mathrm{HCl}, 3 \mathrm{~h})$ were also examined to observe the change in surface morphology. For studying the optical and structural properties of SQR, $10 \mu \mathrm{L}$ of $\mathrm{SQR}$ was coated on glass substrates $\left(1 \times 1 \mathrm{~cm}^{2}\right)$ by FFTMand used to obtain photoluminescence (PL) spectra, UV-vis spectra and XRD patterns.

Characterization and corrosion testing. Optical properties of SQR were investigated by UV-Vis spectrophotometer of Shimadzu (UV-2600) and fluorescence spectrophotometer of Hitachi (F-4600). TEM micrographs were recorded on FEI-TECHNAI G 20 TWIN microscope (with accelerating voltage of $200 \mathrm{kV}$ ). Film samples for TEM were directly lifted on carbon coated $\mathrm{Cu}$ grids. Surface images were recorded on HRSEM, FEI Netherlands (model: Nova Nanosem 450). SSEIS and Tafel polarization curves study was performed on an electrochemical workstation of $\mathrm{CH}$ instruments (CHI7041C). A traditional electrochemical set up of three electrodes was used to perform the experiments: working, with and without SQR deposited Cu substrate as electrode; counter, Metrohm tubular Pt electrode; and reference, Metrohm Ag/ AgCl tubular electrode. Differential Pulse Voltammetry (DPV) experiments were carried out on PGSTAT302, Metrohm Autolab, Netherlands. Diffraction pattern of SQR was recorded with thin film X-ray diffraction system (Rigaku, Japan) equipped with GIXD.

\section{Data Availability}

The data that are analyzed to quote the findings of this paper are available from the corresponding author of the manuscript upon reasonable request.

\section{References}

1. Jafari, Y., Ghoreishi, S. M. \& Nooshabadi, M. S. Polyaniline/Graphene nanocomposite coatings on copper: Electro-polymerization, characterization, and evaluation of corrosion protection performance. Synth. Met. 217, 220-230 (2016).

2. Zhang, D., Cai, Q., He, X., Gao, L. \& Zhou, G. Inhibition effect of some amino acids on copper corrosion in HCl solution. Mater. Chem. Phy. 112, 353-358 (2008).

3. Sherif, E. M. Corrosion Mitigation of Copper in Acidic Chloride Pickling. J. Mater. Eng. Perform. 19, 873-879 (2010).

4. Zhang, D. et al. Intramolecular Synergistic Effect of Glutamic Acid, Cysteine and Glycine Against Copper Corrosion in Hydrochloric Acid Solution. Thin Solid Films 520, 356-361 (2011).

5. Krebs, F. C. Fabrication and processing of polymer solar cells:A review of printing and coating techniques. Solar Energy Materials \& Solar Cells. 93, 394-412 (2009).

6. Pandey, R. K., Singh, A. K., Upadhyay, C. \& Prakash, R. Molecular self-ordering and charge transport in layer by layer deposited poly (3,3'-dialkylquarterthiophene) films formed by Langmuir-Schaefer technique. J. Appl. Phys. 116, 094311-8 (2014).

7. Pandey, R. K., Yadav, S. K., Upadhyay, C., Prakash, R. \& Mishra, H. Surface plasmon coupled metal enhancedspectral and charge transport properties ofpoly(3,3"'-dialkylquarterthiophene) Langmuir Schaefer films. Nanoscale 7, 6083-6092 (2015).

8. Mishra, R., Pandey, R. K., Upadhyay, C. \& Prakash, R. Self-Assembly of Solution-Processable Polyindole via Langmuir-Blodgett Technique: An Insight to Layer-Dependent Charge Transport and Electronic Parameters. Chemistry Select 2, 6009-6015 (2017).

9. Mishra, R., Nirala, N. R., Pandey, R. K., Ojha, R. P. \& Prakash, R. Homogenous dispersion of $\mathrm{MoS}_{2}$ nanosheets in polyindole matrix at air-water interface assisted by Langmuir technique. Langmuir 33, 13572-13580 (2017).

10. Martin, P. M. Handbook of Deposition Technologies for Films and Coatings Science, Applications and Technology, 3rd Edition ISBN 978-0-8155-2031-3 (2010).

11. Pandey, M., Nagamatsu, S., Pandey, S.S., Hayase, S. \& Takashima, W. Orientation Characteristics of Non-regio controlled Poly(3hexyl-thiophene) Film by FTM on Various Liquid Substrates. J. Phys.: Conf. Ser. 704012005 (1-7), https://doi.org/10.1088/1742$6596 / 704 / 1 / 012005$.

12. Soeda, J. et al. Highly Oriented Polymer Semiconductor Films Compressed at the Surface of Ionic Liquids for High Performance Polymeric Organic Field-Effect Transistors. Adv. Mater. 26, 6430-6435 (2014).

13. Pandey, R. K., Singh, A. K. \& Prakash, R. Directed Self-Assembly of Poly (3,3"'-dialkylquarterthiophene) Polymer Thin Film: Effect of Annealing Temperature. J. Phys. Chem. C 118, 22943-22951 (2014).

14. Pandey, R. K. et al. Macroscopic self ordering of solution processible poly (3, $3^{\prime \prime \prime}$-dialkyl quarter thiophene) by floating film transfer method. Journal of Applied Physics 114(1-8), 054309 (2013).

15. Nikhil, Pandey, R. K., Sahu, P. K., Singh, M. K. \& Prakash, R. Fast grown self-assembled polythiophene/graphene oxide nanocomposite thin films at air-liquid interface with high mobility used in polymer thin film transistors. J. Mater. Chem. C 6, 9981-9989 (2018).

16. Tripathi, A. S. M. et al. Anisotropic charge transport in highly oriented films of semiconducting polymer prepared by ribbon-shaped floating film. Appl. Phys. Lett. 112(1-5), 123301 (2018).

17. Noh, J., Jeong, S. \& Lee, J. Y. Ultrafast formation of air-processable and high-quality polymer films on an aqueous substrate. Nat Commun. 7, $12374(2016)$

18. Sprenger, H. E. \& Ziegenbein, W. The Cyclobutenediylium Cation, a Novel Chromophore from Squaric Acid. Angew. Chem. 6, 553-554 (1967). 
19. Patwari, J., Chatterjee, A., Sardar, S., Lemmens, P. \& Pal, S. K. Ultrafast Dynamics in Co-sensitized Photocatalyst under Visible and NIR Light Irradiation. Phys. Chem. Chem. Phys. 20, 10418-10429 (2018).

20. Chen, G. et al. J-aggregation of a squaraine dye and its application inorganic photovoltaic cells. J. Mater. Chem. C 1, 6547-6552 (2013).

21. Gsänger, M. et al. High-Performance Organic Thin-Film Transistors of J-Stacked Squaraine Dyes. J. Am. Chem. Soc. 136, 2351-2362 (2014).

22. Rao, G. H., Venkateswararao, A., Giribabu, L. \& Singh, S. P. Near-infrared unsymmetrical blue and greensquaraine sensitizers. Photochem. Photobiol. Sci. 15, 287-296 (2016).

23. Yum, J. H. et al. Efficient Near-IR Sensitization of Nanocrystalline $\mathrm{TiO}_{2}$ Films by anassymetrical Squaraine dye. J. Am. Chem. Soc. 129, 10320-10321 (2007).

24. Deacon, G. B. \& Phillips, R. J. Relationships between the Carbon-oxygen stretching frequencies of carboxylate complexes and the type of carboxylate coordination. Coord. Chem. Rev. 33, 227-250 (1980).

25. Narayanan, N. et al. Aggregation induced Raman scattering of squaraine dye: Implementation in diagnosis of cervical Cancer dysplasia by SERS imaging. Biosens. Bioelectron. 70, 145-152 (2015).

26. Gopi, A. et al. Modulating FRET in Organic-Inorganic Nanohybrids for Light Harvesting Applications. J. Phys. Chem. C 120, 26569-26578 (2016)

27. Brinkmann, M., Hartmann, L., Biniek, L., Tremel, K. \& Kayunkid, N. Orienting Semi-Conducting $\pi$-Conjugated Polymers. Macromol. Rapid Commun. 35, 9-26 (2014).

28. Sato, S. et al. Air-Stable and High-Performance Solution-Processed Organic Light-Emitting Devices Based on Hydrophobic Polymeric Ionic Liquid Carrier-Injection Layers. Adv. Mater. 30(1-8), 1705915 (2018).

29. Tiwari, M., Gupta, V. K., Singh, R. A., Ji, G. \& Prakash, R. Donor- $\pi$-Acceptor-Type Configured, Dimethylamino-Based Organic Push-Pull Chromophores for Effective Reduction of Mild Steel Corrosion Loss in $1 \mathrm{M} \mathrm{HCl}$. ACS Omega 3, 4081-4093 (2018).

30. Oguzie, E. E. et al. Natural Products for Materials Protection: Mechanism of Corrosion Inhibition of Mild Steel by Acid Extracts of Piper guineense. J. Phys. Chem. C 116, 13603-13615 (2012).

31. Hsieh, Y. P. et al. Complete Corrosion Inhibition through Graphene Defect Passivation. ACS Nano 8, 443-448 (2014).

32. Chidiebere, M. A., Ogukwe, C. E., Oguzie, K. L., Eneh, C. N. \& Oguzie, E. E. Corrosion inhibition and adsorption behavior of Punicagranatum on mild steel in acidic environments: experimental and Theoretical Studies. Ind. Eng. Chem. Res. 51, 668-677 (2012).

33. Srivastava, M. et al. Low cost aqueous extract of Pisumsativum peels for inhibition of mild steel corrosion. J. Mol. Liq. 254, 357-368 (2018).

34. Ji, G., Shukla, S. K., Dwivedi, P., Sundaram, S. \& Prakash, R. Inhibitive effect of Argimone mexicana Plant Extract on acid corrosion of mild steel. Ind. Eng. Chem. Res. 50, 11954-11959 (2011).

35. Ji, G., Anjum, S., Sundaram, S. \& Prakash, R. Musa Paradisica peel extract as green corrosion inhibitor for mild steel in $\mathrm{HCl}$ solution. Corros. Sci. 90, 107-117 (2015)

36. Ji, G., Dwivedi, P., Sundaram, S. \& Prakash, R. Inhibitive effect of Chlorophytum Borivilianum root Extract on mild steel corrosion in $\mathrm{HCl}$ and $\mathrm{H}_{2} \mathrm{SO}_{4}$ solutions. Ind. Eng. Chem. Res. 52, 10673-10681 (2013).

37. Srivastava, M., Tiwari, P., Srivastava, S. K., Prakash, R. \& Ji, G. Electrochemical Investigation of Irbesartan Drug Molecules as an Inhibitor of Mild Steel Corrosion in $1 \mathrm{M} \mathrm{HCl}$ and $0.5 \mathrm{M} \mathrm{H}_{2} \mathrm{SO}_{4}$ Solutions. J. Mol. Liq. 236, 184-197 (2017).

38. Solomon, M. M., Umoren, S. A. \& Abai, E. J. Poly(methacrylic acid)/silver nanoparticles composites: In-situ preparation, characterization and anticorrosion property for mild steel in $\mathrm{H}_{2} \mathrm{SO}_{4}$ solution. J. Mol. Liq. 212, 340-351 (2015).

39. Ji, G., Macia, L. F., Allaert, B., Hubin, A. \& Terryn, H. Odd random phase electrochemical impedance spectroscopy to study the corrosion behavior of Hot Dip Zn and Zn-Alloy coated steel wires in sodium chloride solution. J. Electrochem. Soc. 165, 246-257 (2018).

40. Kumar, S. H. \& Karthikeyan, S. Torsemide and furosemide as green inhibitors for the corrosion of mild steel in hydrochloric acid medium. Ind. Eng. Chem. Res. 52, 7457-7469 (2013).

41. Umoren, S. A., Obot, I. B. \& Gasem, Z. M. Adsorption and corrosion inhibition characteristics of strawberry fruit extract at steel/ acids interfaces: experimental and theoretical approaches. Ionics 21, 1171-1186 (2015).

42. Ji, G., Dwivedi, P., Sundaram, S. \& Prakash, R. Aqueous extract of Argemone mexicana roots for effective protection of mild steel in an $\mathrm{HCl}$ environment. Res. Chem. Inter. 42, 439-459 (2016).

43. Pal, S. et al. Experimental and theoretical investigation of aqueous and methanolic extracts of Prunus dulcis peels as green corrosion inhibitors of mild steel in aggressive chloride media. J. Mol. Liq. 276, 347-361 (2019).

44. Hefni, H. H. H., Azzam, E. M., Badr, E. A., Hussein, M. \& Tawfik, S. M. Synthesis, characterization and anticorrosion potentials of chitosan-g-PEG assembled on silver nanoparticles. Int. J. Bio. Macromol. 83, 297-305 (2016).

\section{Acknowledgements}

Authors are thankful to CIFC, IIT BHU Varanasi for providing research facilities. Authors also want to thank lab mates for their friendly support.

\section{Author Contributions}

Dr. Rajiv Kumar Pandey has analyzed the data related to characterization and growth of Squarine. Ms. Richa Mishra has done the experiments for film formation and transfer of squarine over copper. In fact, the contribution of Dr. Rajiv Kumar Pandey and Ms. Richa Mishra was equal. Dr. Gopal Ji has performed and analyzed all the experiments related to corrosion. The whole work has been performed under supervision of Dr. Gopal Ji in the lab of Prof. Rajiv Prakash.

\section{Additional Information}

Supplementary information accompanies this paper at https://doi.org/10.1038/s41598-019-50092-5.

Competing Interests: The authors declare no competing interests.

Publisher's note Springer Nature remains neutral with regard to jurisdictional claims in published maps and institutional affiliations. 
(c) (i) Open Access This article is licensed under a Creative Commons Attribution 4.0 International License, which permits use, sharing, adaptation, distribution and reproduction in any medium or format, as long as you give appropriate credit to the original author(s) and the source, provide a link to the Creative Commons license, and indicate if changes were made. The images or other third party material in this article are included in the article's Creative Commons license, unless indicated otherwise in a credit line to the material. If material is not included in the article's Creative Commons license and your intended use is not permitted by statutory regulation or exceeds the permitted use, you will need to obtain permission directly from the copyright holder. To view a copy of this license, visit http://creativecommons.org/licenses/by/4.0/.

(C) The Author(s) 2019 